\title{
The relationship between heart rate as an indicator of work hardness and results of dynamometry
}

\author{
Nasrin Sadeghi ${ }^{\mathrm{a}}{ }^{*}$, Hamidreza Tolide-ie ${ }^{\mathrm{b}}$, Fatemeh Ghaderi $^{\mathrm{c}}$ \\ a Instructor, Department of Occupational hygiene, Gonabad University of Medical Sciences, Gonabad, IRAN \\ b Instructor, Department of Public health, Gonabad University of Medical Sciences, Gonabad, IRAN \\ c Occupational hygiene student, Health faculty, Shiraz University of Medical Sciences, IRAN
}

\begin{abstract}
Heart rate is associated with work hardness and increase linearly with its increasing. In the average of energy consumption, heart rate measurement is simple but non-accurate method for calculation of work hardness. Our purpose in this research was to evaluate the relationship between heart rate and dynamometry results with hypothesis of work hardness effectiveness on the human power. This study was conducted on 102 porcelain workers. Participants were selected randomly. The research tools include stethoscope, the dynamometer. Heart rate, and pinch, grip, and back-leg-chest force were measured and relationships between variables were analyzed with Pearson correlation test and independent T-test using Spss 16 software. The average heart rate of participants were $4.11 \pm 1.79$ with minimum 60 and maximum 120 . The average force of pinch, grip, and back-leg-chest were $8.9 \pm 3.20,4.2 \pm 4.5$ and $9.36 \pm 6.55$, respectively. Work hardness for $3.86 \%$ of workers were light, $7.12 \%$ were moderate and $1 \%$ were heavy. Pinch, grip, and back-leg-chest force relation with heart rate were not significant ( $\mathrm{r}=0.01$, $\mathrm{p}=0.85),(\mathrm{r}=-0.03, \mathrm{p}=0.74)$, and $(\mathrm{r}=0.05, \mathrm{p}=0.59)$, respectively. There was no correlation between heart rate and work hardness. So we can’t use the dynamometry results to determine of work hardness.
\end{abstract}

Keywords: Dynamometry, Grip force, Pinch force, back-leg-chest force, Heart rate, Work hardness

\section{Introduction}

\subsection{Work hardness and Heart rate relationship}

Calculation of working load is possible with oxygen consumption measurement during work.[1] Based on measuring oxygen consumption, the workload assessment include direct or indirect methods. One of the direct methods is the application of special devices such as ergometer bicycle. In addition to high cost of these devices, they are more timeconsuming than the indirect methods.

On the other hand, there are easier and cheaper method that can provide similar results. A good measure of overall exertion is heart rate. Heart rate can be a valid estimate of the energy consumption. Heart rate directly associated with work hardness and with increasing work hardness, oxygen uptake increases linearly.

There are accepted guidelines for heart rate levels and exertion and this technique can, for example, help define the relationship between workload and staffing requirements for physically demanding jobs.[2] Heart rate (as a primary indicator of blood supply system performance) and oxygen consumption in the range from light to heavy work (classified according to ILO) are linearly related to each other. Therefore, oxygen consumption can be calculated from the measurement of heart rate. This method is simple and fast.[3] Heart rate is the proper indicator

${ }^{*}$ Corresponding author. E-mail: na.sadeghi@gmail.com 
when energy consumption is moderate (ie 100-140 beats per minute).[1] but measurement of heart rate to calculate the physical workload is not suitable for very severe and very mild works. Heart rate for light, average, heavy and extra heavy work respectively is less than 90, 90-110, 110-130, 130-150 and 150-170 beats per minute.[4] In jobs that require a continuous hand work, cardiovascular capacity evaluation can be used to determine the readiness and suitability of workers for the job. Workers who had high fitness with their job seem to have lower heart rate at rest and work time than workers with low fitness.

\subsection{Dynamometer}

Dynamometry is the process to force measuring. A hand-held dynamometer is a portable device that can be used to obtain more discrete, objective measures of strength during manual muscle testing than can be achieved via traditional MMT.[5-7] It is a simple test and common to measure the power level. It can also determined right-handed or left-handedness of an individual.[8] Hand-held dynamometer can be used as an effective strength measurement tool for the older adult population.[9] Based on the type of dynamometer used, various forces such as pinch, hand, back-leg-chest can be measured. $[10,11]$

\subsection{Review of previous studies}

Nasl-Saraji and et al show that heart rate and Vo2max consumption increases with increase in work load in damming construction workers.[12] In Wang's study the non-dominant hand grip strength were lower than dominant hand, also grip power in men was more than women.[13] Hassani and his colleague report that the right and left hands of men were upper than women.[14] Brent and et al show that Hand-held dynamometry HHD has the potential to be a reliable tool for strength measurements in healthy, strong subjects; however, there are noteworthy limitations with movements where subjects can overpower the testers.[15]

\subsection{Aim of the study}

The aim of the study was to evaluate the relationship between heart rate and dynamometry with work hardness.

\section{Research methods}

\subsection{Samples and devices}

One-hundred and two porcelain factory workers in the morning shift comprise 62 females and 40 males were randomly selected and recruited in the study. After measuring workers' heart rate, pinch and grip forces and the whole body force were determined using the dynamometers. SAEHAN Hydraulic pinch gauge model SH 5005 and SAEHAN Hydraulic hand dynamometer model SH 5003 was used to measure workers' pinch and grip force respectively. Back-legchest dynamometer model SAEHAN-SH 5007 was also used to measure the back-leg-chest force.

\subsection{Heart rate measurement}

Heartbeat was counted and recorded for 60 seconds while working for each sample.

\subsection{Dynamometry procedure}

To measure workers' pinch and grip force, the dynamometer was set according to its manual. Workers were also trained to exert their maximum power to press the handle, before starting the dynamometry. The average of three times of measurement was recorded as hand power. According to the manual of device, workers kept the pressure for 5 second in each measurement and there was a 15 -second rest between each to prevent fatigue in them. Workers' position to measure Heartbeat and performing dynamometry was selected according to their working posture. To measure back-leg-chest force, the participants were asked to stand on device with two legs. To prevent excessive movement of the device pointer, the height of the chain was adjusted based on worker's height. To validate the results of measurements, the dynamometer was calibrated in each use and sufficient rest was given to participants before measurement.

\subsection{Data analysis}

Statistical analysis was performed using SPSS 16. Pearson correlation coefficient was used to evaluate the relationship between continuous variables and independent samples t-test was used to compare means of continuous variables in two groups. $\mathrm{P}<0.05$ was considered statistically significant. 


\section{Findings}

Mean age of participants were $28.2 \pm 4.6$ (range: 18-39) years. $39.2 \%$ of them were men and $60.8 \%$ were women. Heart Rate in $86.3 \%, 12.7 \%$ and $1 \%$ of participants respectively was less than 90 , between 90-110 and between 110-130 beats per minute and their workload respectively was light, moderate and heavy. Statistics of quantitative variables such as age, height, weight, body mass index, heart rate, hand, and pinch and Back-Leg-Chest forces was given in the Table 1.

Table 1

Statistics of quantitative variables in porcelain workers

\begin{tabular}{|l|l|l|l|}
\hline $\begin{array}{l}\text { Statistics } \\
\text { variables }\end{array}$ & Mean \pm SD & Minimum & $\begin{array}{l}\text { Maxi- } \\
\text { mum }\end{array}$ \\
\hline Age (year) & $28.23 \pm 4.59$ & 18 & 39 \\
\hline Pinch force & $5.43 \pm 2.43$ & 2.08 & 18.60 \\
\hline Hand force & $20.34 \pm 9.80$ & 2.60 & 49.30 \\
\hline $\begin{array}{l}\text { Back-Leg-Chest } \\
\text { force }\end{array}$ & $55.65 \pm 36.96$ & 6.60 & 160.30 \\
\hline Heart rate (per min) & $79.17 \pm 11.42$ & 60 & 120 \\
\hline Height $(\mathrm{cm})$ & $162.20 \pm 9.22$ & 142 & 183 \\
\hline Weight $(\mathrm{kg})$ & $60.60 \pm 11.64$ & 39.60 & 92 \\
\hline BMI $\left(\mathrm{kg} / \mathrm{m}^{2}\right)$ & $22.99 \pm 3.82$ & 17.14 & 36.74 \\
\hline
\end{tabular}

The relationship between hand force, pinch force and Back-Leg-Chest force with heart rate based on the Pearson correlation coefficient are shown in Table 2 . It revealed that there were no association between heart rate and results of dynamometry.

Table2

Correlations between Heart rate and the result of pinch, Hand and back leg chest dynamometry

\begin{tabular}{|c|l|c|c|c|}
\hline & & $\begin{array}{c}\text { Pinch } \\
\text { force }\end{array}$ & $\begin{array}{c}\text { Hand } \\
\text { force }\end{array}$ & $\begin{array}{c}\text { Back/Leg/ } \\
\text { Chest force }\end{array}$ \\
\hline $\begin{array}{c}\text { Heart } \\
\text { rate }\end{array}$ & $\begin{array}{l}\text { Pearson } \\
\text { Correlation } \\
\text { coefficient }\end{array}$ & .019 & -.033 & .054 \\
\cline { 2 - 5 } & $\begin{array}{l}\text { p-value (2- } \\
\text { tailed) }\end{array}$ & .851 & .744 & .592 \\
\hline
\end{tabular}

Age, height, weight, body mass index, heart rat, hand force, pinch force and Back-Leg-Chest force was independently compared in two sexes using independent samples t-test. The results of this test are given in Table 3. In this study the hands, pinch and Back-Leg-Chest force in men were more than women and this differences was statistically significant $(\mathrm{p}<0.001)$.

Table3: comparison of continuous variables in two sexes.

\begin{tabular}{|c|c|c|c|}
\hline & $\begin{array}{c}\text { Men } \\
(\mathbf{n}=\mathbf{4 0})\end{array}$ & $\begin{array}{c}\text { Women } \\
(\mathbf{n = 6 2})\end{array}$ & $\begin{array}{c}\text { p- } \\
\text { value }\end{array}$ \\
\cline { 2 - 3 } & Mean \pm SD & Mean \pm SD & \\
\hline Age (years) & $28.45 \pm 3.99$ & $28.09 \pm 4.97$ & 0.7 \\
\hline Height $(\mathrm{cm})$ & $170.18 \pm 7.63$ & $156.79 \pm 5.56$ & $<0.001$ \\
\hline Weight $(\mathrm{kg})$ & $65.47 \pm 11.04$ & $57.29 \pm 10.95$ & 0.001 \\
\hline BMI $\left(\mathrm{kg} / \mathrm{m}^{2}\right)$ & $22.55 \pm 3.10$ & $23.28 \pm 4.24$ & 0.36 \\
\hline Pinch force & $6.81 \pm 2.71$ & $4.54 \pm 1.74$ & $<0.001$ \\
\hline Hand force & $29.52 \pm 7.32$ & $14.42 \pm 5.82$ & $<0.001$ \\
\hline $\begin{array}{c}\text { Back-Leg- } \\
\text { Chest force }\end{array}$ & $94.40 \pm 26.80$ & $30.64 \pm 13.51$ & $<0.001$ \\
\hline $\begin{array}{c}\text { Heart rate (per } \\
\text { min) }\end{array}$ & $79.55 \pm 10.56$ & $78.93 \pm 12.02$ & 0.79 \\
\hline
\end{tabular}

\section{Discussion}

In this study the relationship between work hardness and heart rate was not significant. As well, there was no significant relationship between heart rate and dynamometry forces. Therefore we could not determine the work hardness based on heart rate and force exerted. Nasl-Saraji show that heart rate and Vo2max consumption increases with increase in work load in damming construction workers. Their result upholds the current study results. [12]

In the Wang study pinch force in the men were more than women. [13] The results of this study is consistent with this study. In the present study the relationship between age and with the hand, pinch and back-leg-chest test based on Pearson correlation coefficient is significant. ( $\mathrm{P} \geq 0.05)$. Afshar studied the impact of age on the hand strength, with increasing age, the hand power decreased. [16]

In this study, the difference was not significant between heart rate and age, Mousavi showed similar association in his study. [17]

Verschuren recommended 30 seconds required to measure the force on the dynamometer to high accuracy results. [18] But in the dynamometer manual, 5 seconds is recommended. Lack of communication between the dynamometer and work hardness results in the present study may be due to short-term measure that can be survey in future studies.

Conclusion: This study didn't show significant correlation between heart rate and work hardness and dynamometry results. The dynamometer cannot be good measure to judge about work hardness based on this research results. 


\section{References}

[1] Helandr M. A guide to the ergonomics of manufacturing. Translated by Choobineh A.R. tachr publisher; Shiraz. 2001:155-168.

[2] Dan MacLeod, THE RULES OF WORK A Practical Engineering Guide to Ergonomics, Taylor \& Francis, 2000

[3] Sadeghi Naeini H., The principles of ERGONOMICS in material handling systems (persian), Asana pub., 2000.

[4] Brijer R.S. Introduction to ergonomics. Translated by Motamedzadeh M, Behrozi A, Rssulzadeh Y. institute of labor and social security Publisher; 2002: 285-308

[5] Merlini L, Mazzone ES, Solari A, Morandi L. Reliability of hand-held dynamometry in spinal muscular atrophy. Muscle Nerve. 2002;26(1):64-70

[6] Roebroeck ME, Harlaar J, Lankhorst GJ. Reliability assessment of isometric knee extension measurements with a computer-assisted hand-held dynamometer. Arch PhysMed Rehabil. 1998;79(4):442-448.

[7] Kwoh CK, Petrick MA, Munin MC. Inter-rater reliability for function and strength measurements in the acute care hospital after elective hip and knee arthroplasty. ArthritisCare Res. 1997;10(2):128-134.

[8] Hand grip strength test, 2011, Available at: http://www.topend sport.com.

[9] Arnold CM, Warkentin KD, Chilibeck PD, Magnus CR., The reliability and validity of handheld dynamometry for the measurement of lower-extremity muscle strength in older adults. Strength Cond Res. 2010 Mar;24(3):815-24.

[10]Pinch gaug, 2011, Available at: http://www.bleng.com.

[11]Hand grip strength, 2011, Available at: http://www.wikipedieia.com.

[12] Nasl-Saraji Jebraeil, Zeraati Hojat, Pouryaghub Gholamreza, Gheibi Leila, Musculoskeletal disorders study in damming construction workers by Fox equation and measurement heart rate at work, Salamate kare iran, 5: 1,2. 2008.

[13] Wang CY. Hand dominance and grip strength of older Asian adults. Percept Mot Skills. 2010 Jun; 110(3 Pt 1):897-900.

[14] Hasani mehraban A, Hosseini F. Study hand strength of senior's resident nursing homes Tehran city. Iran medical journal. Spring 2004; 11(39).

[15]Brent M. Kelln, Patrick O. McKeon, Lauren M. Gontkof, Jay Hertel, Hand-Held Dynamometry: Reliability of Lower Extremity Muscle Testing in Healthy, Physically Active, Young Adults, Journal of Sport Rehabilitation, 2008, 17, 160-170.

[16]Afshar A.R, Eatemadi A,Mirzatoloei F. Whether surgery carpal tunnel syndrome affects the power hand? Uromia medical journal. Spring 2008; 19(1).

[17] Mosavi najarcola A. Effect of age on the prevalence of upper extremity musculskeletal disorder in the textile factory worker Qaemshahr. Tehran medical journal. Payesh quarterly. Spring 2007; 6(2).

[18] Verschuren O, Ketelaar M, Takken T, Van Brussel M, Helders PJ, Gorter JW., Reliability of hand-held dynamometry and functional strength tests for the lower extremity in children with Cerebral Palsy. Disabil Rehabil. 2008;30(18):1358-66. 